\title{
EXPERIMENTS SIMULATION AND DESIGN TO SET TRAFFIC LIGHTS' OPERATION RULES
}

\author{
Jaime Espinoza Mondragón \\ Master Student, Instituto Tecnológico de Celaya, México \\ José Alfredo Jiménez García, José Martin Medina Flores and José Antonio Vázquez \\ López \\ Research Professor, Instituto Tecnológico de Celaya, México
}

Sandra Téllez Vázquez

Research Professor, Universidad Politécnica de Guanajuato, México

\begin{abstract}
In this paper it is used the experimental design to minimize the travel time of motor vehicles, in one of the most important avenues of Celaya City in Guanajuato, Mexico, by means of optimal synchronization of existing traffic lights. In the optimization process three factors are considered: the traffic lights' cycle times, the synchrony defined as stepped, parallel and actual, and speed limit, each one with 3 evaluation levels. The response variables to consider are: motor vehicles' travel time, fuel consumption and greenhouse effect gas (CO2) emissions. The different experiments are performed using the simulation model developed in the PTV-VISSIM software, which represents the vehicle traffic system. The obtained results for the different proposed scenarios allow to find proper levels at which the vehicle traffic system must be operated in order to improve mobility, to reduce contamination rates and decrease the fuel consumption for the different motor vehicles that use the avenue.
\end{abstract}

\section{INTRODUCTION}

In the city of Celaya, Guanajuato there are released every year 873,111 tons of $\mathrm{CO}_{2}$ (Aranda García et al., 2013), this due the increasing demand of vehicles that use these routes in the city. It is worth to mention that Blvd. Adolfo López Mateos (Blvd. ALM ) is one of the busiest routes and for this reason it is worth to reduce travel time of any vehicle that use this road system. Exhaust emissions from motor vehicles contain more than 100 kinds of harmful substances, including the main component of particulate matter, carbon dioxide $\left(\mathrm{CO}_{2}\right)$, carbon monoxide (CO), nitrogen oxide (NOX) and hydrocarbons (HC) etc. (Zhipeng, Lizhu, Shanqzhi, \& Yeqing Qian, 2014).

The severity of the problem rises when the traffic flow is interrupted and the delays and start-stops occur frequently. These phenomena are regularly observed at traffic intersections, junctions, and at signalized roadways (Pandian, Gokhale, \& Goshal, 2009). During idle period, the engine will consume more fuel and will release more $\mathrm{CO}_{2}$ emissions than in travel time (M. Barth \& K. Boriboonsomsin, 2009). Although a study reported that acceleration and deceleration of a car had an emission rate greater than at idle period (H.C. 
Frey et al., 2003). The relationship of speed, duration in the system (Blvd. ALM.), acceleration and deceleration of vehicles affects the carbon dioxide emission and fuel consumption. Helbing (2001) found that the increase of vehicle speed from 10 to 40, leads to increase of fuel consumption by 2 to 4 times, therefore the carbon dioxide emission would increase in the same extent. While Chunxiao \& Shimamoto (2012), report that trip duration, trip distance and speed variation are the main factors that affect the carbon dioxide emission per vehicle. Henein, N., et al. (2000) studied the effect of start transients in the fuel consumption and emissions of $\mathrm{HC}$ and NOx using direct injection diesel engines and corroborated that stop the engine reduces the fuel consumption, also demonstrated the shutdown time had an important influence in the NOx emissions.

The impact of different transport policies on traffic demand, air quality and population exposure to air pollution can be analysed on a microscale (Hülsmann, Gerike, \& Ketzel, 2014). The aim of this paper is to reduce the duration times in the system of the vehicles that use the road Blvd. ALM, applying experiment design and simulation techniques. The experiment can be considered as part of scientific process and one of the means to understand the operation of systems and processes (Montgomery, 2004). The simulation is the process to design and develop a computer model of a system or model and to perform experiments using this model with the purpose to understand the system behavior or assess several strategies with the ones can be operated the system (Shannon, 1988). With regards DOE (Design of Experiments) there were proposed 27 treatments (scenarios obtained when considering three factors). The factors under studio were cycle time, the synchronization of the traffic lights, and the speed limits. The levels for the cycle time were defined in 100, 120 and 140 seconds, the levels for synchronization were defined as current state, parallel and staggered; and the speed limits were defined considering the transit regulations. The aim was to minimize the travel time and therefore the $\mathrm{CO}_{2}$ emissions and fuel consumption.

The synchronization of the traffic lights is extremely important to improve traffic flow. Cal $\&$ Mayor (1994) report that there are 4 traffic lights' coordination systems of fixed time type, although there were only used tree and they are: simultaneous or parallel system, where all traffic lights have the same indication of time. 2. Alternating or step system where the traffic lights of near intersections, grouped, show alternating indications throughout the route. This improves the vehicles circulation compared with the first one. 3. Flexible progressive system, where it is possible that each intersection with traffic light automatically varies in several ways, setting several schedules to subdivide the cycle, with the predefined time to give preference in hours of maximum demand. The reason traffic signals exist is to assign the right-of-way at intersections. Control of a particular direction is partitioned into three traffic light phases: green, yellow, and red. The interval from when the green phase begins and the red phase ends is the cycle time (Florin \& Olariu, 2015).

A promising and cost-effective way to obtain driving pattern data for all individual vehicles in a traffic stream is the use of microscopic traffic simulation models (Smit, Smokers, \& 
Rabé, 2007). It was developed the simulation model that represent the route system of Blvd. Adolfo López Mateos (ALM) with the aim of PTV VISSM software where the experiments were carried out according to the proposed experiments design, in order to define which of them is the one that offers the best conditions of vehicle traffic system.

\section{SYSTEM TO SIMULATE}

\subsection{Description of System to Simulate}

The system to simulate was defined like the Blvd. Adolfo López Mateos that runs from Plan de Iguala Street up to Velázquez Street and vice versa. This system has 14 traffic lights and their corresponding intersections, as shown in Figure 1.

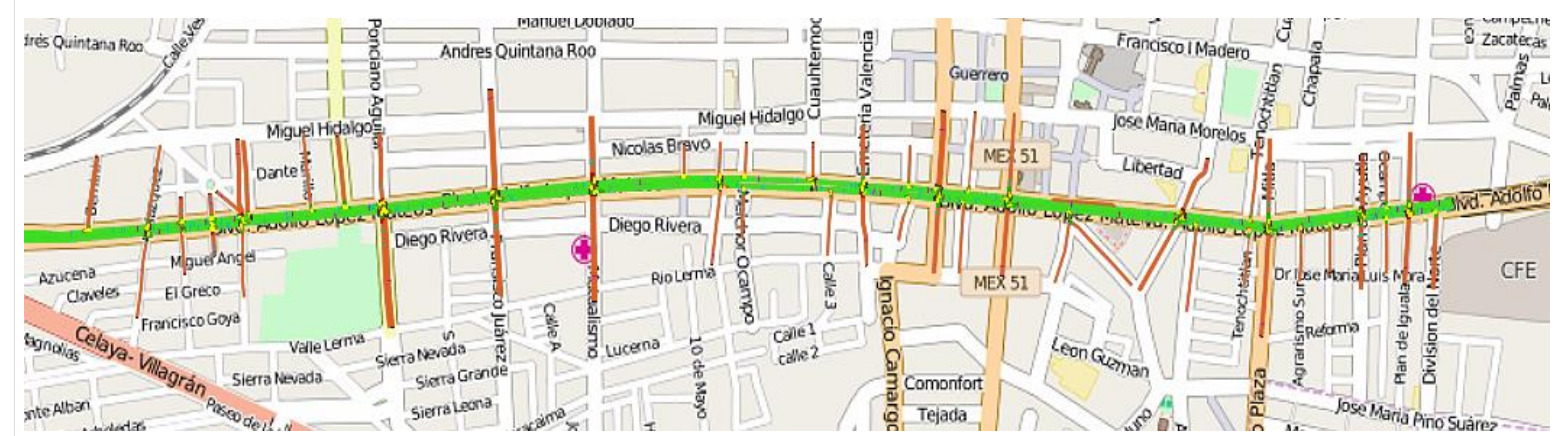

Fig. 1 - System to Simulate (Blvd. ALM) and model development

\section{METHOD}

The steps suggested by Banks (2005) to perform a successful simulation project were followed, and are the following:

\subsection{Data collection}

Vehicle capacity studies were performed and these data were taken during intense traffic hours from 13 to $14 \mathrm{~h}$, where the amount of cars driving by that Boulevard and the cars traveling by each intersection was recorded in the Table 2., 10 cycles were recorded in each intersection. The distance between intersections was measured and is listed in Table 1. The cycle time of each traffic light was also taken.

\begin{tabular}{|c|c|c|c|c|c|c|c|c|c|c|c|c|c|}
\hline & $\begin{array}{c}\text { Plande guala } \\
\text { aAyutla }\end{array}$ & $\begin{array}{c}\text { Plande Ayulla } \\
\text { Plaza }\end{array}$ & $\begin{array}{c}\text { Antonio Plaza a } \\
\text { Contázal }\end{array}$ & $\begin{array}{l}\text { Cortázar a } \\
\text { Allende }\end{array}$ & \begin{tabular}{|c|} 
Allende a \\
Benito Juárez
\end{tabular} & \begin{tabular}{|c|} 
Benito Juárez \\
a Emeteria
\end{tabular} & \begin{tabular}{|l|} 
Emeteria a \\
Chaurand
\end{tabular} & $\begin{array}{l}\text { Concha a } \\
\text { Javier Mina }\end{array}$ & \begin{tabular}{|c|} 
Mina a \\
Abasolo
\end{tabular} & \begin{tabular}{|l|} 
Abasoloa \\
Fco. Juárez
\end{tabular} & \begin{tabular}{|l|} 
Fco. Juárez \\
a Ponciano
\end{tabular} & \begin{tabular}{|c|} 
Ponciano \\
aPiña
\end{tabular} & \begin{tabular}{|c|} 
Piña a \\
Velázquez
\end{tabular} \\
\hline Distances & $114.276 \mathrm{~m}$ & $230 \mathrm{~m}$ & $212.079 \mathrm{~m}$ & $422.547 \mathrm{~m}$ & $173.938 \mathrm{~m}$ & $183.437 \mathrm{~m}$ & $123.186 \mathrm{~m}$ & $230.637 \mathrm{~m}$ & $308.624 \mathrm{~m}$ & $239.43 m$ & $275.12 m$ & $326.716 \mathrm{~m}$ & $248.31 \mathrm{~m}$ \\
\hline
\end{tabular}

Table 1 - Distance between intersections 

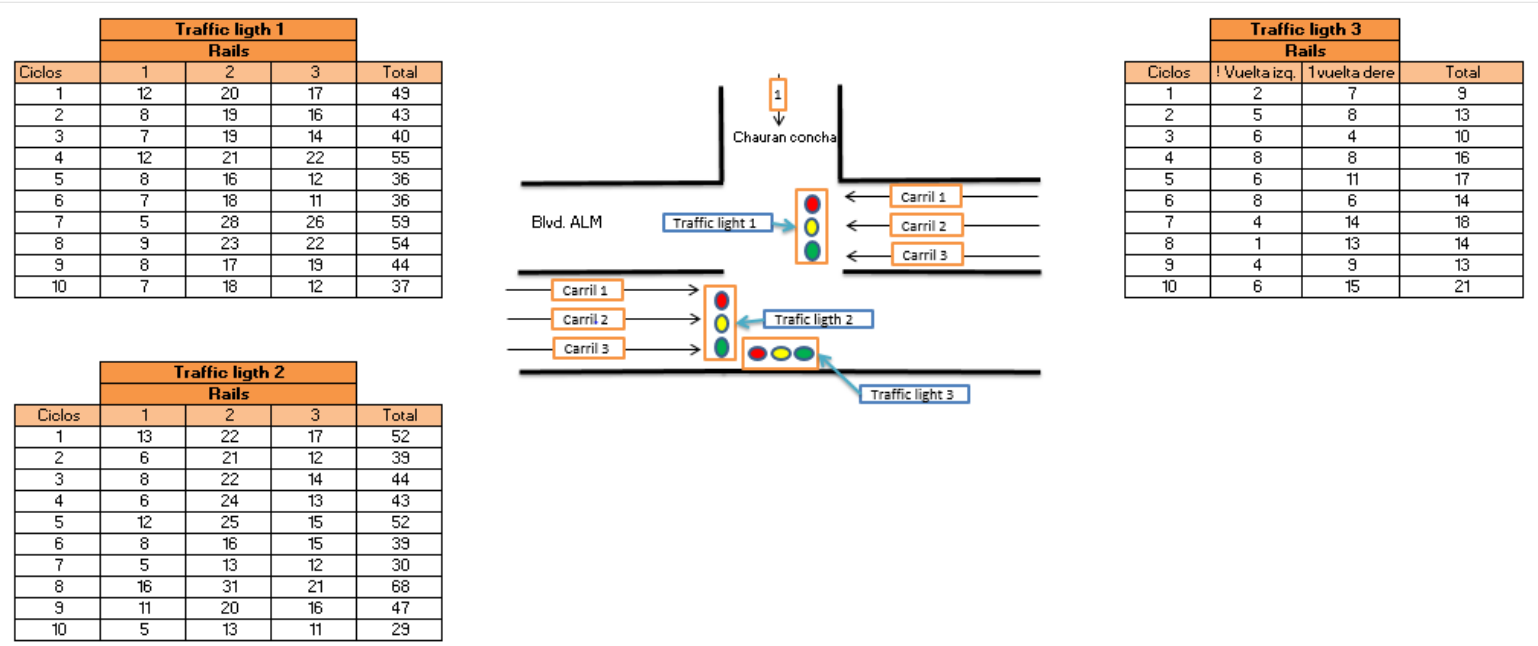

Traffic light 3

Table 2 - Cars counting

\subsection{Data analysis}

The obtained data (the amount of cars driving by that boulevard and the cars traveling by each intersection) were subject to goodness-of-fit test with the aim to define the probability distributions, with the help of STAT:FIT statistics tooling, included in Promodel software. The test is based in how well is the fit we have between the occurrence frequency and the expected frequencies that are obtained from the hypothetical distribution (Walpole R., 2007). Then it was defined that the arrivals distribution in each intersection followed Poisson distribution. This was performed in every line of Blvd. ALM and its corresponding intersections, but it is only shown the line 1 of intersection Fco. Juárez and Blvd. ALM in Figure 2.
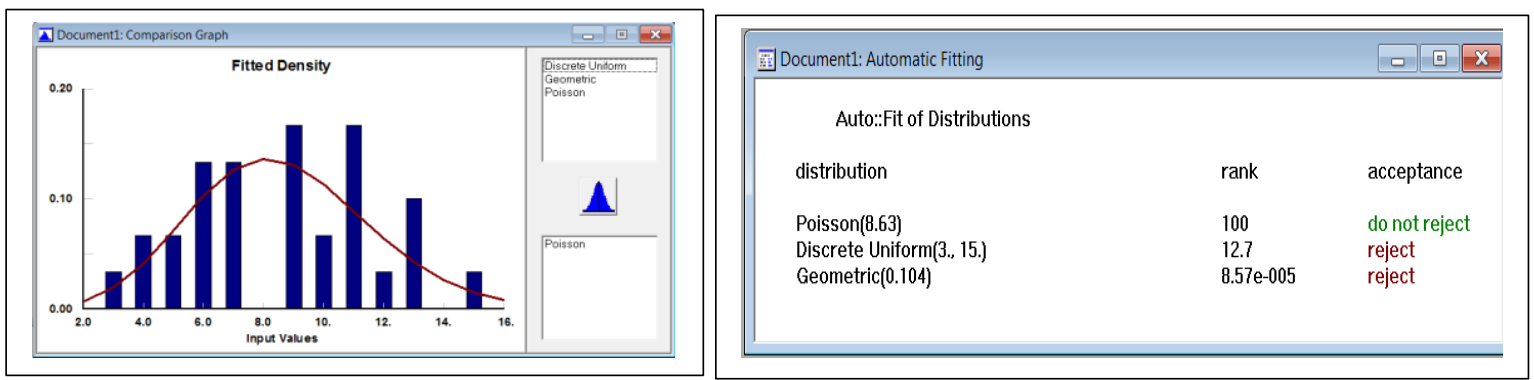

Fig. 2. Data analysis at intersection Blvd. ALM and Fco. Juárez line 1

\subsection{Model construction}

As it was indicated, the model was built with the support of PTV VISSIM 7 software since it is specific purpose software for the vehicular flow analysis with a micro simulation technique. In Figure 1 it can be seen the resulting layout model. The data collected were entered into the software. Traffic lights' operation rules presenting this boulevard is a flexible progressive synchronization, the speed limit is $50 \mathrm{~km} / \mathrm{h}$, with a cycle in their traffic lights ranging from $140 \mathrm{sec}$ and $139 \mathrm{sec}$. The results of the current system are shown below in the Table 3 and Table 4. These results were obtained with Vissim 7. 


\begin{tabular}{|l|l|l|r|r|}
\hline Count & Timelnt & VehicleTravelTimeMeasurement & Vehs(All) & TravTm(All) \\
\hline 1 & $600-4200$ & 1: West to East & 96 & 411.85 \\
\hline 2 & $600-4200$ & 2: East to West & 140 & 423.87 \\
\hline
\end{tabular}

Table 3 - Time in the System (Blvd. ALM) with the Current System

\begin{tabular}{|c|c|c|c|c|c|c|c|c|c|c|c|c|c|c|}
\hline TIMENT & MOVEMENT & QIEN & QLENMAX & $\begin{array}{l}\text { VEHS } \\
\text { (ALL) } \\
\end{array}$ & \begin{tabular}{|l|} 
PERS \\
(ALLL) \\
\end{tabular} & \begin{tabular}{|c|} 
VEHDELAY \\
(ALL) \\
\end{tabular} & \begin{tabular}{|c|} 
PERSDELAY \\
(ALL) \\
\end{tabular} & $\begin{array}{c}\text { STOPDELAY } \\
\text { (ALL) }\end{array}$ & $\begin{array}{l}\text { STOPS } \\
\text { (ALL) } \\
\end{array}$ & \begin{tabular}{|c|} 
MOVEMENTI \\
DIRECTION \\
\end{tabular} & $\begin{array}{c}\text { EMISSIONS } \\
\text { CO }\end{array}$ & \begin{tabular}{|c|} 
EMISSIONS \\
NOX \\
\end{tabular} & $\begin{array}{c}\text { EMISSIONS } \\
\text { VOC }\end{array}$ & \begin{tabular}{|c|c|} 
FUEL \\
CONSUMPTION \\
\end{tabular} \\
\hline $600-4200$ & 1-1: Blvd.ALM 1@95.5-1: Blvd. ALM 1@3214.9 & 10.28 & 76.55 & 140 & 140 & 189.74 & 189.74 & 132.11 & 3.94 & $E-W$ & 1555.659 & 302.675 & 360.539 & 22.255 \\
\hline $600-4200$ & 1-2: BIVd. ALM 2@362.2-2: Blvd. ALM 2@3479.9 & 7.02 & 48.03 & 96 & 96 & 175.97 & 175.97 & 140.3 & 3.36 & W-E & 946.748 & 184.203 & 219.418 & 13.544 \\
\hline $600-4200$ & & 10.16 & 198.66 & \#\#册1 & 10966 & 67.52 & 67.52 & 50.62 & & & 32933.144 & 6407.593 & 7632.574 & 471.147 \\
\hline
\end{tabular}

Table 4 - Emissions and fuel consumption (Current System)

As can be seen, the time a car needs to drive the system from east to west is of 423.87 seconds and from west to east is of 411.85 seconds. The fuel consumption is of 471.147 gallons $\left(1,783.485\right.$ liters). In total the cars that use this Boulevard emit $3,959.3367 \mathrm{~kg}$ of $\mathrm{CO}_{2}$. Therefore, a system is sought to reduce the travel time on the Boulevard.

\subsection{Model verification and validation}

The verification corroborates that the correct translation of the model to computer software that properly works is performed (Barceló, 1998). On the other hand, the validation refers to define if the conceptual model is a proper representation of the system in study (Barceló, 1998). The verification was done by observation when executing the simulation model, given the obtained experiment after the collection and data analysis stages. Also, the validation was done statistically by a procedure of hypothesis and confidence interval by means differences, comparing the software outputs with data obtained from the real system. The test was done with the aim of Minitab software version 17, the results are shown in Figure 3.

T and CI test two samples: Real system, Vissim

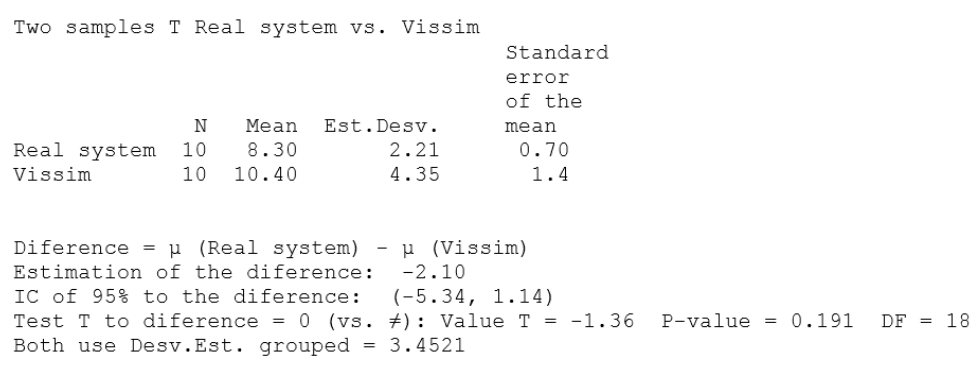

\section{Fig. 3. Results confidence interval and hypothesis testing in Minitab 17}

The results of the test shows that according a confidence level $95 \%$ the difference between means, is -5.35 and 1.14. In this interval the zero is included so there is no difference between the mean. According to the hypothesis testing, the p-value is 0.191 , so is not possible reject the null hypothesis that asserts that the means are equal. This procedure was applied to all the intersections. 


\subsection{Experimental}

Once the model has been validated and there is certainty that the model truly represents the real system, the following step is to perform experiments to find the best system performance. A factorial design consists in performing all possible combinations of levels for several factors (Kuehl, 2001), in this investigation, a full factorial design was used. Therefore, three main factors were defined like synchrony of the traffic lights, cycle time of the traffic lights and speed of the cars. In the synchrony factor three levels were defined: current state, parallel and staggered. For the cycle time factor three levels were defined: 100, 120 and 140 seconds. Finally, for speed factor three levels were defined, within safety rules laws: 40, 50 and 60 kilometers per hour. With this information a full factorial $3^{3}$ design with two repetitions was proposed, then there were obtained $3 \times 3 \times 3=27$ treatments and 54 runs, with the help of Minitab 17. The output variables are: Time in the system (Blvd. ALM), $\mathrm{CO}_{2}$ emissions and fuel consumption.

To estimate $\mathrm{CO}_{2}$ emissions using the following relationship: 1 liter of Petrol (Gasoline) produce $2.22 \mathrm{~kg}$ of $\mathrm{CO}_{2}$ (GREENPEACE, 1991), The rate of carbon dioxide emission of the $\mathrm{n}$-th vehicle is defined like the amount of carbon dioxide emission per kilometer, this is described in the Equation (1) (Zhu, 2013):

$$
\Delta E_{n}=\frac{1000}{D_{n}} \cdot E_{n}
$$

Where $E_{n}$ is the amount of $\mathrm{CO}_{2}$ emissions $(\mathrm{kg})$ of $\mathrm{n}$ vehicles and $D_{n}$ denotes the distance traveled by n vehicles.

In the following section there is more information about traffic lights synchronization.

\subsubsection{Flexible Progressive System (Current)}

This system is the one that such Boulevard is using, since every intersection with traffic light varies automatically in several aspects, sub-dividing the cycle, with preset time to give preference in hours of maximum demand. The cycle time of 14 traffic lights with their intersections differs in this system, some are of 140 seconds, other of 139 and some others of 141 , this causes that cars need to stop very often at the traffic lights, increasing fuel consumption and $\mathrm{CO}_{2}$ emissions.

\subsubsection{Simultaneous or Parallel System}

The proposal was that the cycle time for the 14 traffic lights with their intersections consider the same indication at the same time, this means that different scenarios were proposed, each one considering a fixed time of 100,120 and 140 seconds.

\subsubsection{Alternating or Step System (staggered)}

In this way of synchronizing the traffic lights of near intersections, there are shown the 
alternating indications, throughout the Blvd. ALM. The speed of the vehicles in order to have band of $100 \%$ it is represented in equation (2) (Cal \& Mayor, 1994).

$$
V=\frac{7.2 D}{C}
$$

Where: $V=$ Progression speed between intersections $(\mathrm{km} / \mathrm{h}), D=$ Distance intersections $(\mathrm{m})$ and $C=$ Cycle duration (s).

$$
V=\frac{d}{t}
$$

According to this, there is set at which time must be turned on the green light in the following traffic light using the general equation of speed, Equation (3), for the different speeds (40, 50 and $60 \mathrm{~km} / \mathrm{h}$ ), which is listed in Table 5. It is worth to mention that the coordination of

\begin{tabular}{|c|c|c|c|c|c|c|c|c|c|c|c|c|c|}
\hline & $\begin{array}{c}\begin{array}{c}\text { Plan de Iguala a } \\
\text { Ayutla }\end{array} \\
\end{array}$ & \begin{tabular}{|c|} 
Plan de Ayutla a \\
Plaza
\end{tabular} & \begin{tabular}{|c} 
Antonio Plaza a \\
Cortázar
\end{tabular} & $\begin{array}{l}\text { Cortázar a } \\
\text { Allende }\end{array}$ & \begin{tabular}{|c|} 
Allende a \\
Benito Juárez
\end{tabular} & $\begin{array}{c}\text { Benito Juárez a } \\
\text { Emeteria }\end{array}$ & $\begin{array}{l}\text { Emeteria a } \\
\text { Chaurand }\end{array}$ & $\begin{array}{c}\text { Concha a Javier } \\
\text { Mina }\end{array}$ & Mina a Abasolo & $\begin{array}{c}\text { Abasolo a Fco. } \\
\text { Juárez }\end{array}$ & \begin{tabular}{|c|}
$\begin{array}{c}\text { Fco. Juárez a } \\
\text { Ponciano }\end{array}$ \\
\end{tabular} & Ponciano a Piña & $\begin{array}{c}\text { Piña a } \\
\text { Velázquez }\end{array}$ \\
\hline Distanc & 114.276 & 230 & 212.079 & 422.547 & 173.938 & 183.437 & 123.186 & 230.637 & 308.624 & 239.43 & 275.12 & 326.716 & 248.31 \\
\hline $50 \mathrm{~km} / \mathrm{h}$ & 2 & 5 & 8 & & & 4 & & 5 & & & 5 & 6 & \\
\hline $60 \mathrm{~km} / \mathrm{h}$ & 2 & 4 & 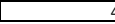 & & & 3 & & 4 & & 4 & 4 & 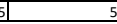 & \\
\hline
\end{tabular}
this system embraces from Plan de Iguala Street to Velázquez.

Table 5 - Time of changes to green from one intersection to other

\section{RESULTS}

\subsection{Warm up period}

The warm up period is the time required to stabilize the system. In this case a stabilization period of 10 minutes was defined, then the model executed in $1 \mathrm{~h}$ with $10 \mathrm{~min}$, in order to avoid the software giving results within the simulation time of $1 \mathrm{~h}$.

\subsection{Results of experiments}

The 54 proposed scenarios were run and the results are listed in Table 6. As output variables there were measured the time in the system (Blvd. ALM), $\mathrm{CO}_{2}$ emissions and fuel consumption. There were added the results of both trips that is the cars that travel from east to west, and vice versa, since no matter the trip or way they are moving, all use the same route. The runs were performed in random, according to the design given by Minitab 17 software. It is worth to mention that data are averages. 


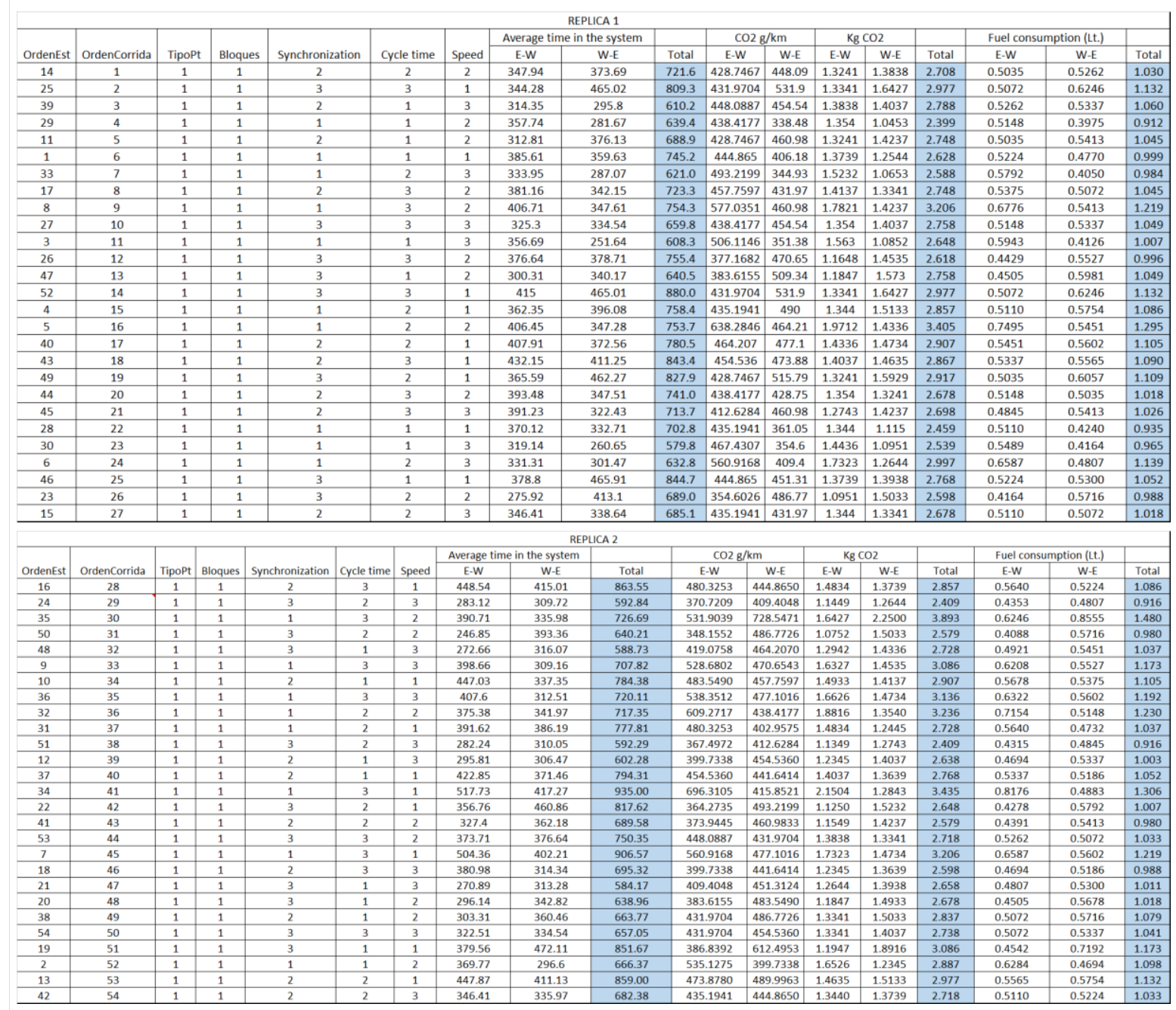

Table 6 - Result of experiments $3^{3}$

The obtained results were introduced to Minitab software, to perform a complete factorial design $3^{3}$ with two repetitions and the following results were obtained.

In first place, it was verified the assumptions of normality, constant variance and independence, as it can be seen in Figure 4.
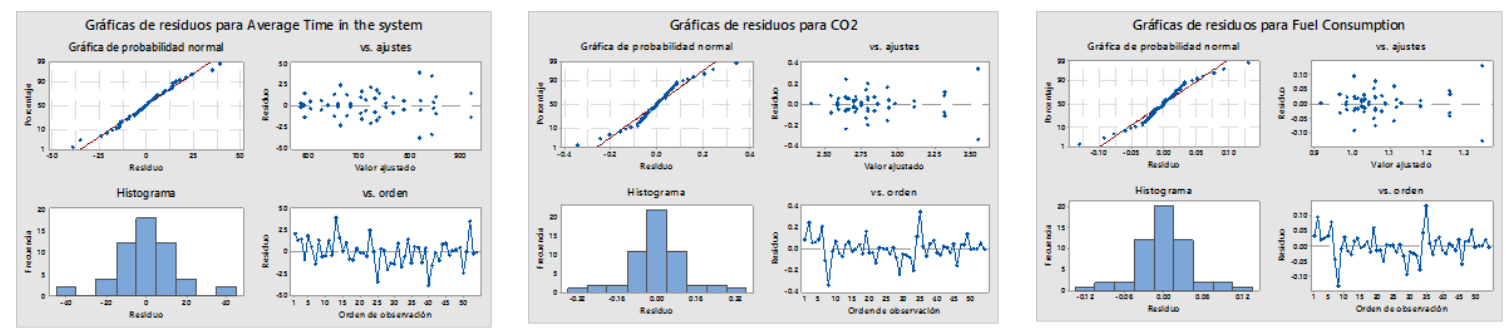

Fig. 4 - Verification of assumptions

Three figures are showed in Figure 4, in every one it can be noted that the assumptions are met, in the left superior corner it can be noted that most of data are grouped around the line, 
demonstrating that the normality is met. In the right superior corner there are plotted the assumptions against residues and there is no funnel shape, which means that the assumption of constant variance is met. Finally, in the right inferior corner, is plotted the order of observation versus residue and it can be noted a random behavior, fulfilling the independence assumption. Bellow there is presented each of the resulting ANOVA:

Factorial general regression: Average time in the syst vs. Synchronization, Cycle time, Speed

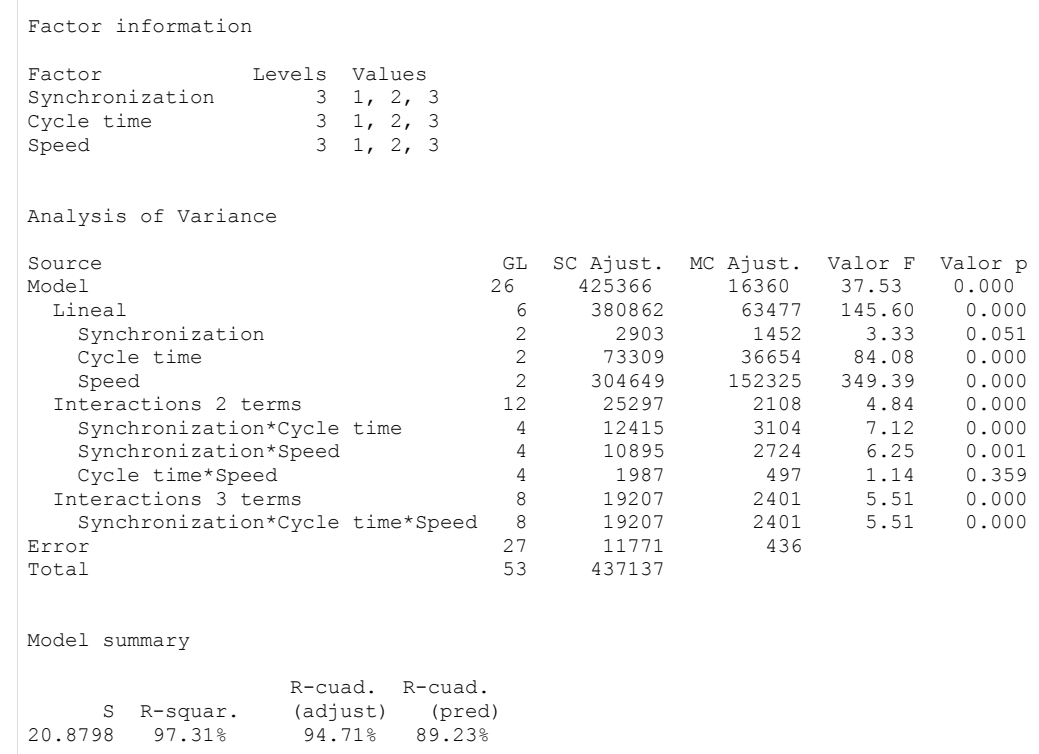

Fig. 5 - ANOVA Average time in the system

In the Figure 5, is analyzed the effect that the three studied factors have on the time the cars remain in the system. It can be noted that the three factors significantly affect the response variable, except the effect of iteration formed by cycle time and speed ( $\mathrm{p}$ value is greater than 0.05 ). There is a R-squared value of $97.31 \%$, which means that $97.31 \%$ of variability is explained by the model.

On the other hand, when comparing the three factors against the $\mathrm{CO}_{2}$ response variable, the following ANOVA is obtained (see Figure 6). 


\section{Factorial general regression: CO2 vs. Synchronization, Cycle time, Speed}

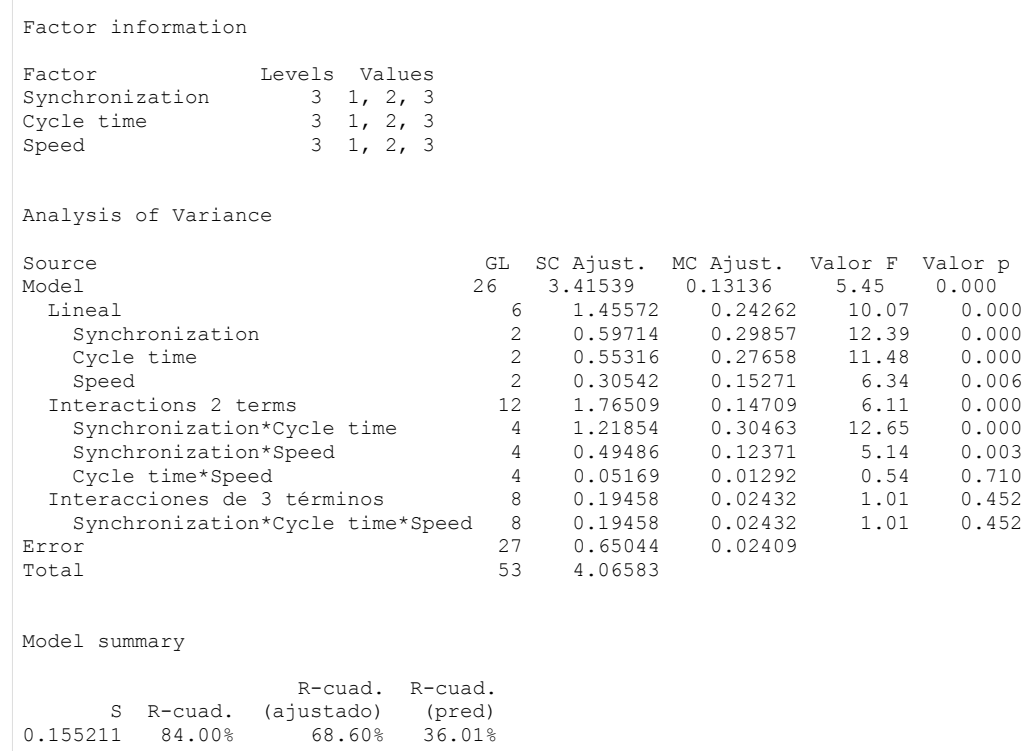

Fig. 6 - ANOVA CO2

In this case it can be observed that $\mathrm{CO}_{2}$ is affected by the three factors since $\mathrm{p}$ value is less than 0.05 . Where a coincidence is detected is in the effect of double iteration between cycle time and speed, in this case it can also be concluded that this effect of double iteration does not affect the response variable $\mathrm{CO}_{2}$. The $\mathrm{R}$-squared value $84 \%$, then it is considered that $84 \%$ of variability is explained by the model.

Finally, there is a third ANOVA, where is analyzed the interaction between the three factors and the output variable fuel consumption (see Figure 7).

Factorial general regression: Fuel Consumption vs. Synchronization, Cycle time, Speed

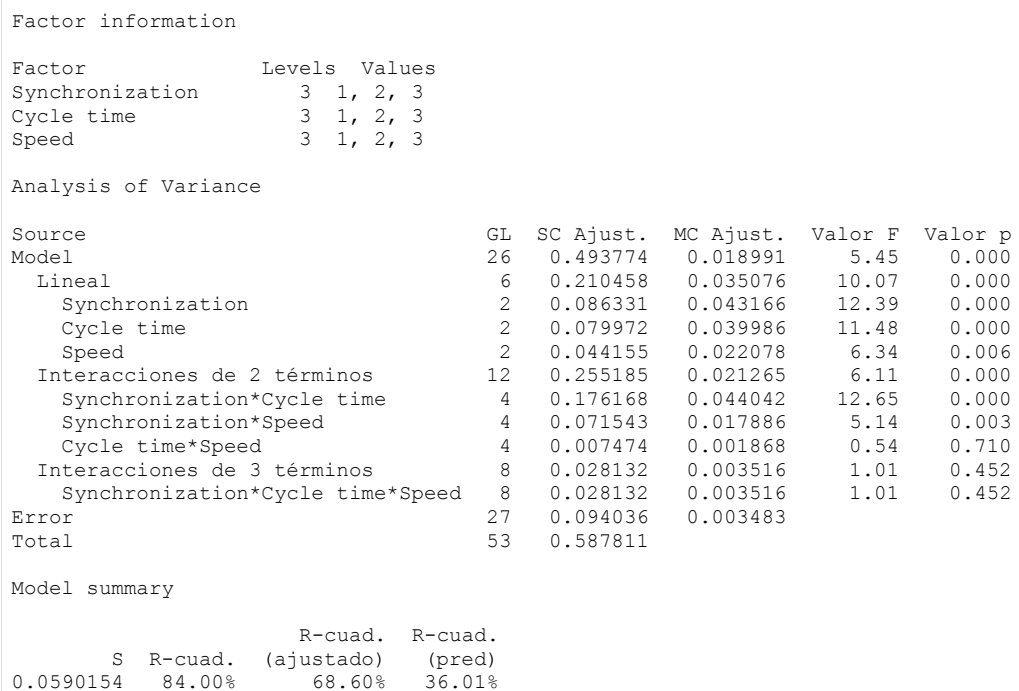

Fig. 7 - ANOVA Fuel consumption 
In this ANOVA, as in the previous two, it can be noted that the effect of double interaction between cycle time and speed, does not significantly affects the fuel consumption ( $p$ value $=0.710$ ). Also, it is noted that the triple effect of the three factor neither significantly affects fuel consumption ( $\mathrm{p}$ value of 0.452 ).

The aim of this paper is to analyze the results under experimental design approach to define the best factors combination that improve the system conditions, that is to minimize the response variables, like duration in the system, $\mathrm{CO}_{2}$ emissions and fuel consumption. The Figure 8 shows the graphic of main effects.

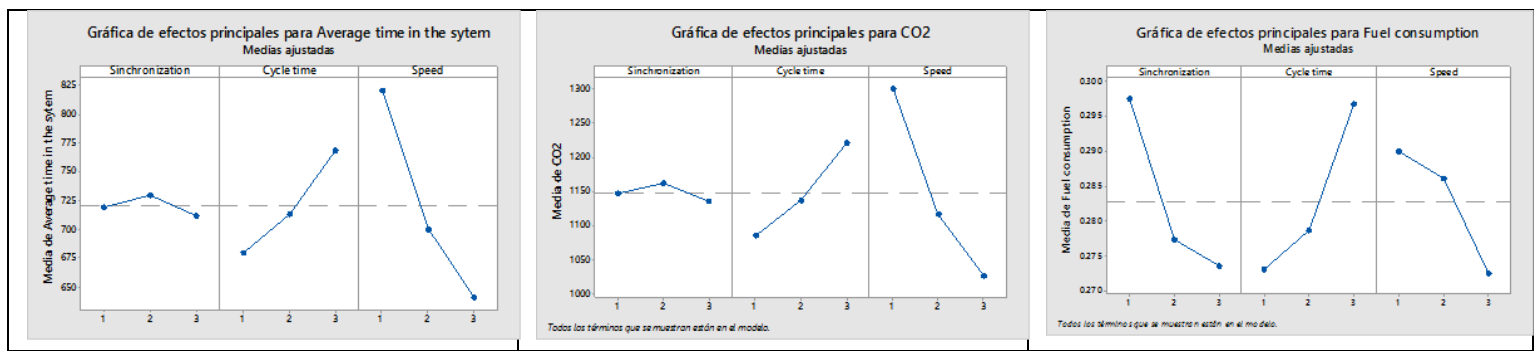

Fig. 8 - Graphics of main effects

In Figure 8, it can be noted that in general, regardless the output variable (duration in the system, $\mathrm{CO}_{2}$, or fuel consumption), the levels in the rules in which the system must be operated, in order to minimize all response variables are: synchronization 3, cycle time 2, speed 3. In other words, the lights should synchronize in staggered, the traffic light cycle should be from 120 seconds and the speed limit must be set to $60 \mathrm{~km} / \mathrm{hr}$. When executing the simulation model with the conditions proposed according to the results of experiment designs, the following results are obtained.

\begin{tabular}{|l|l|l|r|r|}
\hline Count & Timelnt & VehicleTravelTimeMeasurement & Vehs(All) & TravTm(All) \\
\hline 1 & $600-4200$ & 1: West to East & 106 & 315.23 \\
\hline 2 & $600-4200$ & 2: East to West & 152 & 274.60 \\
\hline
\end{tabular}

Table 7 - Time in the System (Blvd. ALM) with the Obtained System

In the Table 7, the time a car needs to drive the system from east to west is of 274.60 seconds and from west to east is of 315.23 seconds. As for fuel consumption and some pollutants, they are listed in Table 8. 


\begin{tabular}{|c|c|c|c|c|c|c|c|c|c|c|c|c|c|c|}
\hline TIMENT & MOVEMENT & QLEN & QLENMAX & $\begin{array}{l}\text { VEHS } \\
\text { (ALL) }\end{array}$ & PERS (ALL) & $\begin{array}{c}\text { VEHDELAY } \\
\text { (ALL) }\end{array}$ & $\begin{array}{c}\text { PERSDELA } \\
Y \text { (ALL) }\end{array}$ & $\begin{array}{c}\text { STOPDELA } \\
\text { Y(ALL) }\end{array}$ & $\begin{array}{l}\text { STOPS } \\
\text { (ALL) }\end{array}$ & \begin{tabular}{|c|} 
MOVEMENTI \\
DIRECTION \\
\end{tabular} & $\begin{array}{c}\text { EMISSIONS } \\
\mathrm{CO}\end{array}$ & $\begin{array}{c}\text { EMISSION } \\
\text { SNOX } \\
\end{array}$ & $\begin{array}{c}\text { EMISSIONS } \\
\text { VOC }\end{array}$ & $\begin{array}{c}\text { FUEL } \\
\text { CONSUMPTION } \\
\end{array}$ \\
\hline $600-4200$ & 1-1:BVIV.ALM1@77.01:BVId.ALM1@3229.8 & 8.49 & 58.28 & 152 & 152 & 109.77 & 109.77 & 71.13 & \multicolumn{2}{|c|}{ 2.38E-W } & 1246.076 & 242.441 & 288.79 & 17.827 \\
\hline $600-4200$ & 1-1:Blvd.ALM1@77.02: BVvd.ALM2@3498.7 & 8.49 & 58.28 & 9 & 9 & 172. & 172. & 128.2 & \multicolumn{2}{|c|}{ 3.33 EE } & 59.324 & 11.542 & 13.749 & 0.849 \\
\hline $600-4200$ & 1-1:Blivd.ALM1@77.0-4: Fo. Juarez abaj@@15.7 & 8.49 & 58.28 & 5 & 5 & 135.72. & 135.72. & 99.29 & \multicolumn{2}{|c|}{ 2.6E-S } & 41.038 & 7.985 & 9.511 & 0.587] \\
\hline $600-4200$ & 1-1:Blbd.ALM1@77.06: Mariano Abassol@@10.7 & 8.49 & 58.28 & 55 & 55 & 74.77 & 74.77 & 46.34 & \multicolumn{2}{|c|}{$1.67 \mathrm{E}-\mathrm{N}$} & 302.377 & 58.832 & 70.079 & 4.326 \\
\hline $600-4200$ & 1-1-:Blvd.ALM1@77.0-8: Mina arriba@13.1 & 8.49 & 58.28 & 66 & 66 & 74.25 & 74.25 & 47.5 & \multicolumn{2}{|c|}{$1.7 \mathrm{E}-\mathrm{N}$} & 331.809 & 64.558 & 76.9 & 4.747 \\
\hline $600-4200$ & 1-2:BVIVd.ALM2@346.12:BBvd.ALM2@34988.7 & 4.94 & 4..08 & 106 & 106 & 145.22 & 145.22. & 109.63 & \multicolumn{2}{|c|}{$3.33 \mathrm{~W}-\mathrm{E}$} & 993.612 & 1933.321 & 230.279 & 14.215 \\
\hline $600-4200$ & 1-62:Rafael sanni@@75.451: Melchor Ocampo 2@18.7 & o & o & o & of & & & & \multicolumn{2}{|c|}{ S.S } & 0 & 0 & 0 & 0] \\
\hline $600-4200$ & 1-62: Rafael sanzi@@75.458:Leonardo de vinci@17.7 & o & o & 10 & 10 & 2.82 & 2.82 & 1.16 & \multicolumn{2}{|c|}{$0.115-5$} & 4.037 & 0.786 & 0.936 & 0.058 \\
\hline $600-4200$ & 1-62: Rafael sanio@75.4-60: Rafael Sanci@@17.6 & 0 & 0 & 1 & 1 & 0.53 & 0.53 & 0 & \multicolumn{2}{|c|}{ os-N } & 0.224 & 0.044 & 0.052 & 0.003 \\
\hline $600-4200$ & 1-62: Rafael sanzio@75.41-1091: Guadalupe a Sostenes@5. & o & o & 0 & o & & & & \multicolumn{2}{|r|}{ s-s } & 0 & 0 & o & 0 \\
\hline $600-4200$ & 1 & 9.27 & 159.68 & 10991 & 10991 & 52.98 & 52.98 & 38.37 & \multicolumn{2}{|c|}{1.27 Total } & 30521.566 & 5938.388 & 7073.668 & 436.646 \\
\hline
\end{tabular}

Table 8 - Emissions and fuel consumption

Table 8 shows how many cars use the system, in total 10,991 cars per hour; as for fuel consumption in an hour the cars use a total of 436.646 gallons (1,652,885 liters). As for Blvd. ALM the 152 cars going from west to east use 17.827 gallons $(67,483$ liters), an average of 0.117 gallons ( 0.443 liters) of fuel and the 106 cars going from west to east use 14.215 gallons (53.810 liters), an average of 0.134 (0.507 liters). As for $\mathrm{CO}_{2}$ emissions, the cars from east to west emit in average $149.811 \mathrm{~kg} \mathrm{CO}_{2}$, in average $0.985 \mathrm{~kg}$ of $\mathrm{CO}_{2}$ per car and the cars from west to east emit in average $119.457 \mathrm{~kg}$ of $\mathrm{CO}_{2}$, in average 1.130 of de $\mathrm{CO}_{2}$ per car. In total in one hour with the system $3,2,3$ are emit $3,669.4 \mathrm{~kg}$ of $\mathrm{CO}_{2}$.

\section{CONCLUSIONS}

Considering that the criteria was to reduce each of the response variables like duration time in the Blvd. ALM, the $\mathrm{CO}_{2}$ emissions and fuel consumption, it is concluded that the best way to configure the traffic lights is the staggered system. These variables are directly related since the lesser a car stays in the system, saves more fuel and emits fewer pollutants by $\mathrm{CO} 2$. By means of synchronization of traffic lights in staggered, it is reduced the times drivers need to stop in the intersections and this scenario favors the reduction of pollutants and fuel consumption. An important improvement as result of this proposal is that when synchronizing the lights in staggered, the number of times that it is required to accelerate and decelerate are reduced. Another factor that can affect duration time in the system, is the traffic light cycle time, in this sense, it is proposed to configure the traffic lights of Blvd to 120 seconds, since according to the demand and the results from design of experiments it minimizes the response variables. Finally, as it was expected, the speed that minimized duration time in the system, is the highest allowed of $60 \mathrm{~km} / \mathrm{hr}$.

\section{ACKNOWLEDGMENTS}

This study was developed thanks to the financial support of Conacyt, by means of scholarship number 403927. We also thanks to Prodep due the support granted by the project ITCEL-PTC-020. And to Instituto Tecnológico de Celaya for funding the trip for showing the results at CIT 2016 Congress and we also thank to PTV GROUP to ease an 18 months license for performing my master studies. 


\section{REFERENCES}

Aranda García, L. A., Bárcenas Blancarte, C., Contreras Juárez, C. M., Cornejo Ramírez, J. L., De la Luz González , G., \& García Salazar, I. (2013). SEMARNAT. Recuperado el 13 de Enero de 2016, de Programa de Gestión para Mejorar la Calidad del aire de Salamanca, Celaya e Irapuato 2013-2022: http://www.semarnat.gob.mx/sites/default/files/documentos/calidadaire/proaire_sal amanca-celaya-_irapuato_2013_2022.pdf

Banks, J. (2005). DISCRETE-EVENT System Simulation ( $3^{\circ}$ ed.). PEARSON PRENTICE HALL.

Barceló, J. (1998). Simulación de Sistemas Discretos. Madrid: Isdefe.

Cal, R., \& Mayor, S. (1994). INGENIERIA DE TRANSITO (7ºd.). Alfaomega.

Chunxiao, L., \& Shimamoto, S. (2012). An Open Traffic Light Control Model for Reducing Vehicles CO2 Emissions Based on ETC Vehicles. IEEE Transactions on Vehicular Technology, 61, 97-110.

Florin, R., \& Olariu, S. (2015). A survey of vehicular communications for traffic signal optimization. Vehicular Communications(2), 70-79.

GREENPEACE. (1991). DIESEL: HECHOS MÁS DESTACADOS SOBRE LAS EMISIONES. Recuperado el 15 de FEBRERO de 2016, de BVSDE: http://www.bvsde.paho.org/bvstox/e/fulltext/diesel/diesel.pdf

H.C. Frey, A. Unal, N. M. Rouphail, \& J. D. Colyar. (2003). On-road measurement of vehicle tailpipe emissions using a portable instrument. J. Air Waste Manage. Assoc., 53(8), 992-1002.

Helbing, D. (2001). Traffic and related self-driven many-particle systmes. Reviews of Modern Physics, 73, 1067.

Henein, N., Taraza, D., Chalhoub, N., Lai, M., \& Bryzik, W. (2000). Exploration of the Contribution of the Start/Stop Transients in HEV Operation and Emissions. SAE Technical, 2000-01-3086.

Hülsmann, F., Gerike, R., \& Ketzel, M. (2014). Modelling traffic and air pollution in an integrated approach - the case of Munich. Urban Climate(10), 732-744.

Kuehl, R. O. (2001). Diseño de experimentos (Principios estadísticos de diseño y análisis de investigación). Thomson Editores.

M. Barth, \& K. Boriboonsomsin. (2009). Traffic congestion and greenhouse gases. Access(35), 2-9.

Montgomery, D. C. (2004). Diseño y analisis de experimentos. México: Limusa Wiley.

Pandian, S., Gokhale, S., \& Goshal, A. (2009). Evaluating effects of traffic and vehicle characteristics on vehicular emissions near traffic intersections. Transportation Research Part D(14), 180-196.

Shannon, R. E. (1988). SIMUALCIÓN DE SISTEMAS (2 ed.). TRILLAS.

Smit, R., Smokers, R., \& Rabé, E. (2007). A new modelling approach for road traffic emissions: VERSIT+. Transportation Research Part D: Transport and Environment(12), 414-422.

Taguchi, G. (1987). System of Experimental Design: Engineering Methods to Optimize Quality and Minimize Cost. New York: UNIPUB/Kraus International: White Plains.

Walpole R., M. R. (2007). Probabilidad y estadística para ingenieros. México: Pearson, Prentice Hall.

Zhipeng, L., Lizhu, C., Shanqzhi, X., \& Yeqing Qian. (2014). Analytical studies of CO2 emission in a mixed traffic flow with different vehicles. PhysicaA(413), 320-328.

Zhu, W.-X. (2013). Analysis of CO2 emission in traffic flow and numerical tests . Physica A, 4787-4792. 
